\title{
Hemiplegic shoulder pain in people with stroke: present and the future
}

\author{
Praveen Kumar*,1 \\ ${ }^{1}$ Department of Allied Health Professions, University of the West of England, Bristol, England, UK \\ *Author for correspondence: Tel.: +0117 3288829; Praveen.Kumar@uwe.ac.uk
}

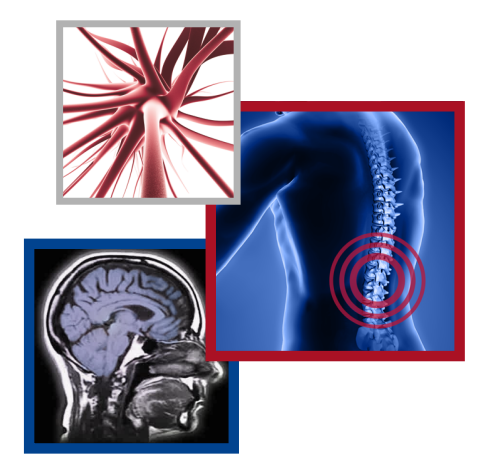

First draft submitted: 30 September 2018; Accepted for publication: 2 November 2018; Published

online: 25 January 2019

Keywords: chronic pain • hemiplegic shoulder pain • rotator cuff injuries • stroke

Hemiplegic shoulder pain (HSP) is one of the four most common medical complications following stroke [1], with a reported incidence of between 30 and 65\% depending upon the population studied and the method of assessment used [2-5]. Several prospective studies reported that almost a third of stroke survivors developed shoulder pain within 6 months of their stroke and $65 \%$ of these patients continued to experience this problem even several months after stroke [3-6]. Chronic HSP may develop over time and is thought to be due to treatment-resistant structural injury and, abnormal posture of the hemiplegic shoulder that damages the surrounding tissues [7]. HSP is associated with a reduction in functional use of the arm, interference with rehabilitation, higher rates of depression and poorer quality of life [4-6].

\section{HSP \& central pain}

Shoulder pain following stroke has been described as a collection of complex problems [8]. Clinical diagnosis is based on the source of shoulder pain which includes altered sensitivity to the pain stimulus, shoulder-hand syndrome and pain arising from the malaligned joints or shortened muscles [9]. Understanding of HSP is, however, complicated by difficulty in distinguishing shoulder pain from central post-stroke pain as both of these can be present in patients with stroke $[8,9]$.

The prevalence of central post-stroke pain in patients with stroke is between 1 and $12 \%$ and it is most likely to be present in patients with sensory impairment [9]. Central sensitization, defined as an increased response of nociceptive neurons in the CNS to normal afferent input can also play an important role in HSP $[8,9]$.

\section{Risk factors}

Causes of HSP are often multifactorial and can be broadly classified into neurological (paralysis, spasticity, altered sensation and neuropathic pain) and mechanical factors (shoulder subluxation, soft tissue injuries such as rotator cuff tears, bicipital tendonitis, muscle imbalance, weakness and altered scapula position) [7].

Few cohort studies have identified loss of motor control as one of the risk factors for HSP. Lindgren et al. [4] in their 1-year follow-up study recruited 416 patients with first time stroke and reported that lost or impaired arm motor function and a high National Institutes of Health Stroke Scale score were predictors of HSP. In this study, HSP was seen in a comparatively larger proportion of the total group of 327 patients $(22 \%)$ within the first 4 months after stroke. Similarly, another study $(\mathrm{n}=58)$, found that patients with left sided hemiplegia, decreased passive range of abduction movement at 4 months and those with pain at 4 months were at risk of having persistent shoulder pain at 1 year [10]. Another recent study reported that shoulder pain during movement at 2 weeks was a predictor of HSP during movement at 6 and 12 weeks after stroke [11].

De Baets [12] in their exploratory study reported that patients with shoulder pain had increased activity of upper fibers of trapezius, reduced activity of lower fibers of trapezius, serratus anterior and delayed or limited activity of infraspinatus muscle. The muscle imbalance in the scapula region which is common after stroke could be a potential risk factor for HSP.

Association between glenohumeral subluxation (GHS) and HSP has been a controversial issue. Of 14 studies included in a systematic literature review, seven showed an association while another seven showed no association, 
suggesting that not all patients with GHS necessarily experience shoulder pain [13]. Findings on the association between subluxation and pain are controversial and this may be attributable, in part, to the methodological differences of the studies reviewed. These include type of study design, time of onset of stroke, patients' selection criteria, sample size and the wide range of tools used for the assessment of both subluxation and pain.

The patients with stroke can experience a high incidence of HSP even in the apparent absence of GHS. Preexisting asymptomatic shoulder related problems, common in older healthy people [14] may become painful in the affected shoulder as a consequence of muscle weakness joint immobility and soft tissue changes following stroke [15]. Abnormal posture of the affected shoulder due to spasticity, reflex sympathetic dystrophy, adhesive capsulitis and restricted joint range of the shoulder could damage the surrounding soft tissues in patients with stroke leading to pain [16]. Therefore, the extent of tissue damage in the shoulder region may not necessarily be related to the degree of GHS, instead, it might depend upon how often and how long the affected arm is left hanging unsupported causing passive overstretching and resultant injury to the tissue [16].

In addition, other sources of pain such as soft tissue injuries including tendinitis of the long head of the biceps and supraspinatus are found to be significantly associated with HSP [5,17]. Kim [17] reported that poor arm motor function, indicated by a poor National Institutes of Health Stroke Scale item 5 score (odds ratio $=3.0$; 95\% CI: $1.1-7.7$ ) and the presence of supraspinatus tendon pathology (odds ratio $=4.2 ; 95 \%$ CI: $1.4-12.9$ ), were associated with HSP at 3 and 6 months.

\section{Assessment/outcomes}

The majority of studies report assessment of HSP using visual analog scale (VAS) $[5,16]$ or verbal rating scale $[2,4]$. VAS is considered a well-known measure for pain and has been reported to be valid within a variety of settings; however, its use on people with stroke has been questioned because of its inadequacy in capturing the complexities of pain [18]. VAS is often found to be used in conjunction with other forms of assessment as an additional resource for measuring pain and is rarely used on its own. Additionally, due to the subjectivity of pain, self-reporting is currently the most valid method of measuring pain and VAS is continually used as a method to assess pain despite its limitations.

\section{Interventions}

Several systematic reviews have been published in this area and a wide range of interventions have been reported in the literature. Current management includes physiotherapy, massage therapy, strapping, slings and other supports to minimize glenohumeral subluxation, local interventions such as nerve blocks and botulinum toxin type A intramuscular injections and electrical stimulation [19]. Positive outcomes were noted with the use of corticosteroid injections and electrical stimulation and conflicting results were seen regarding the use of botulinum toxin type $\mathrm{A}$ in chronic patients with stroke.

A few recent studies reported beneficial effects of electrical stimulation for people with HSP. Chaung et al. [20], in their small sample of $\mathrm{n}=38$ patients (mean age: $61 \pm 10$ years, time since stroke: $32.68 \pm 53.07$ months) reported that electromyography triggered electrical stimulation with bilateral arm training was effective in reducing pain in both subacute and chronic patients with stroke. Similarly, another recent randomized controlled trial reported improvement in pain but not in joint range of motion, upper limb function and activities of daily living after application of electrical stimulation in 36 patients with stroke [21].

\section{Future: assessment \& treatment}

With such a large range of potential causative factors, it is important that clinicians use a consistent approach for the assessment of HSP to deliver more targeted and effective treatments.

An algorithm for the assessment and management of HSP has been described in the Scottish Stroke Guidelines [22] that recommends people with new onset of HSP be screened for pain and treatment provided accordingly. However, this pathway does not incorporate a detailed assessment process for various pathologies (capsulitis, rotator cuff tears, subacromial bursitis) that can inform clinical decision-making. A structured process is required that will facilitate people with HSP to comprehensively describe the nature and impact of their problem. Accurate clinical assessment is vital as this will help improve patient-clinician communication, have psychological benefits for patients with chronic pain and help establishing targeted management plans [23]. In routine musculoskeletal practices, patients with shoulder pain undergo a thorough assessment including subjective, objective and special tests for identifying specific problems for shoulder pain [24]. 
Prevalence of rotator cuff tears increases in people with HSP. A recent study reported that patients with stroke $(\mathrm{n}=55)$ with muscle strength $\leq 3$ on the Medical Research Council grading scale were more likely to have shoulder pain and rotator cuff tears [25]. Therefore, rehabilitation of rotator cuff should be considered for the management of HSP. Evidence from people with shoulder pain in the general population suggests that using concentric and eccentric exercises are effective in reducing shoulder pain. In a study, 36 patients with rotator cuff tendinopathy, were included and randomly allocated to an isolated eccentric exercise group ( $\mathrm{n}=20$, mean age $=50 \pm 10$ years) or a conventional exercise group $(\mathrm{n}=16$, mean age $=48 \pm 12$ years) [26]. After 26 weeks, both groups showed improvement in VAS scores, suggesting that exercises and training programs are beneficial in reducing shoulder pain.

To conclude, evidence suggests that there is a need for establishment of a standardized assessment process for HSP to improve decisions about treatment. By doing a robust holistic assessment on symptoms and impact of HSP, other biopsychosocial issues associated with HSP may also be identified that would otherwise be missed. This will allow offering other treatment options including referral to various services. Evidence from routine musculoskeletal practices could be adapted and tested on patients with HSP to improve pain and functional outcomes.

Financial \& competing interests disclosure

The author has no relevant affiliations or financial involvement with any organization or entity with a financial interest in or financial conflict with the subject matter or materials discussed in the manuscript. This includes employment, consultancies, honoraria, stock ownership or options, expert testimony, grants or patents received or pending, or royalties.

No writing assistance was utilized in the production of this manuscript.

\section{Acknowledgements}

The author would like to thank C McCabe (University of West of England, Bristol, Royal United Hospital NHS Foundation Trust, Bath); A Turton, M Cramp (University of West of England, Bristol); S Ashford (London North West University Healthcare NHS Trust, London) and M Smith (NHS Lothian) for critical discussions/comments on the topic area and Robert Jones (Clinical Specialist Stroke Physiotherapist, South Bristol community Hospital) for critical review of the manuscript.

\section{References}

1. McLean DE. Medical complications experienced by a cohort of stroke survivors during inpatient, tertiary-level stroke rehabilitation. Arch. Phys. Med. Rehabil. 85, 466-469 (2004).

2. Adey-Wakeling Z, Arima H, Crotty MIncidence and associations of hemiplegic shoulder pain poststroke: prospective population-based study. Arch. Phys. Med. Rehabil. 96, 241-247 (2015).

3. Adey-Wakeling Z, Liu E, Crotty $\mathrm{M}$ et al. Hemiplegic shoulder pain reduces quality of life after acute stroke: a prospective population-based study. Am J. Phys. Med. Rehabil. 95, 758-763 (2016).

4. Lindgren I, Jonsson A, Norrving B, Lindgren A. Shoulder pain after stroke: a prospective population-based study. Stroke 38, 343-348 (2007).

5. Huang YC, Liang PJ, Pong YP, Leong CP, Tseng CH. Physical findings and sonography of hemiplegic shoulder in patients after acute stroke during rehabilitation. J. Rehabil. Med. 42, 21-26 (2010).

6. Paolucci S, Iosa M, Toni D et al. Prevalence and time course of post-stroke pain: a multicenter prospective hospital-based study. Pain Med. 17, 924-930 (2016).

7. Vasudevan JM, Brownie BJ. Hemiplegic shoulder pain: an approach to diagnosis and management. Phys. Med. Rehabil. Clin. N. Am. 25, 411-437 (2014).

8. Kalichman L, Ratmansky M. Underlying pathology and associated factors of hemiplegic shoulder pain. Am. J. Phys. Med. Rehabil. 90, 768-780 (2011).

9. Kilt H, Finnerup NB, Jensen TS. Central post-stroke pain: clinical characteristics, pathophysiology, and management. Lancet Neurology 8, 857-868 (2009).

10. Lindgren I, Lexell J, Jönsson AC, Brogardh C. Left-sided hemiparesis, pain frequency, and decreased passive shoulder range of abduction are predictors of long-lasting poststroke shoulder pain. PM R 4, 561-568 (2012).

11. Ada L, Preston E, Langhammer B, Canning CG. Profile of upper limb recovery and development of secondary impairments in patients after stroke with a disabled upper limb: an observational study. Physiother. Theory Pract. 11, 1-7 (2018).

12. De Baets L, Jaspers E, Janssens L, Van Deun S. Characteristics of neuromuscular control of the scapula after stroke: a first exploration. Front. Hum. Neurosci. 17, 1-8 (2014).

13. Kumar P, Saunders A, Ellis E, Whitlam S. Association between glenohumeral subluxation and shoulder pain in patients with post-stroke hemiplegia: a systematic review. Phys. Ther. Rev. 18, 90-100 (2013). 
14. Yamaguchi K, Tetro MA, Blam O, Evanoff BA, Teefey SA, Middleton WD. Natural history of asymptomatic rotator cuff tears: a longitudinal analysis of asymptomatic tears detected sonographically. J. Shoulder Elbow Surg. 10, 199-203 (2001).

15. Carr JH, Shepherd RB. Stroke Rehabilitation: Guidelines for Exercise and Training to Optimise Motor Skill. Butterworth Heinemann, Oxford, UK (2003).

16. Barlak A, Unsal S, Kaya K, Sahin-Onat S, Ozel S. Post stroke shoulder pain in Turkish stroke patients: relationship with clinical factors and functional outcomes. Int. J. Rehabil. Res. 32, 309-315 (2009).

17. Kim YH, Jung SJ, Yang EJ, Paik NJ. Clinical and sonographic risk factors for hemiplegic shoulder pain: a longitudinal observational study. J. Rehabil. Med. 46, 81-87 (2014).

18. Tyson SF, Brown P. How to measure pain in neurological conditions? A systematic review of psychometric properties and clinical utility of measurement tools. Clin. Rehabil. 28, 669-686 (2014).

19. Viana R, Pereira S, Mehta S, Miller T, Teasell R. Evidence for therapeutic interventions for hemiplegic shoulder pain during the chronic stage of stroke: a review. Top. Stroke Rehabil. 19, 514-522 (2012).

20. Chuang LL, Chen YL, Chen CC et al. Effect of EMG-triggered neuromuscular electrical stimulation with bilateral arm training on hemiplegic shoulder pain and arm function after stroke: a randomized controlled trial. J. Neuroeng. Rehabil. 14, 1-12 (2017).

21. Zohu M, Li F, Lu W, Wu J, Pei S. Efficiency of neuromuscular electrical stimulation and transcutaneous nerve stimulation on hemiplegic shoulder pain: a randomized controlled trial. Arch. Phys. Med. Rehabil. 99, 1730-1739 (2018).

22. Scottish Intercollegiate Guidelines Network. Management of Chronic Pain (SIGN Publication no. 136). Edinburgh, UK (2013). http://www.sign.ac.uk/assets/sign136.pdf

23. Dromerick AW, Edwards DF, Kumar A. Hemiplegic shoulder pain syndrome: frequency and characteristics during inpatient stroke rehabilitation. Arch. Phys. Med. Rehabil. 89, 1589-1593 (2008).

24. Petty NJ. Neuromusculoskeletal examination and assessment: a handbook for therapists. Churchill Livingstone 2013(4), 253-270 (2011).

25. Yi Y, Shim JS, Kim K et al. Prevalence of the rotator cuff tear increases with weakness in hemiplegic shoulder. Ann. Rehabil. Med. 37, 471-478 (2013).

26. Deiaco B, Habets B, van Loon C, van Grinsven S, van Cingel R. Eccentric versus conventional exercise therapy in patients with rotator cuff tendinopathy: a randomized, single blinded, clinical trial. Knee Surg. Sports Traumatol. Arthrosc. 25, 2051-2059 (2017). 